\title{
Malignant carcinoid arising within a mature cystic teratoma of the pelvis
}

\author{
Michael Kuncewitch ${ }^{1}$, Kavin G. Shah ${ }^{1}$, Alan Kadison ${ }^{2}$, Ernesto P. Molmenti ${ }^{1}$, James Sullivan ${ }^{2}$ \\ 1. Department of Surgery, Hofstra North Shore - LIJ School of Medicine 2. Department of Surgery, Division of Surgical \\ Oncology, Hofstra North Shore - LIJ School of Medicine
}

Correspondence: Michael Kuncewitch. Address: 350 Community Drive, Room 2233, Manhasset NY 11030, USA. Telephone: 516-562-2249. E-mail: mkuncewtic@nshs.edu

Received: February 14, 2012

Accepted: May 2, 2012

Published: June 1, 2012

DOI : $10.5430 /$ jst.v2n3p56

URL: http://dx.doi.org/10.5430/jst.v2n3p56

\begin{abstract}
Carcinoids are rare neuroendocrine tumors encountered most commonly in the gastrointestinal tract and bronchopulmonary tree. While carcinoids are perhaps best distinguished by their ability to cause the carcinoid syndrome through secretion of vasoactive peptides and amines, the vast majority are asymptomatic. We herein describe the case of a 68 year-old woman who presented with weight gain and local compressive symptoms from a known pelvic cystic teratoma, which was found to contain a well-differentiated malignant carcinoid at the time of surgical excision.
\end{abstract}

\section{Key words}

Carcinoid, Cystic teratoma, Dermoid cyst

\section{I ntroduction}

Malignant Carcinoids are rare neuroendocrine tumors that arise mostly commonly in the gastrointestinal tract and the bronchopulmonary system. Rarely, these tumors have been encountered in the reproductive organs and other endocrine organs throughout the body. Though they are distinguished by their ability to cause the carcinoid syndrome through their ability to secrete bioactive peptides and amines, approximately $90 \%$ of carcinoids are nonfunctional ${ }^{[1]}$. Thus, the vast majority of patients are asymptomatic and their carcinoids are diagnosed incidentally during imaging or surgery for other causes. We herein describe the case of a 68 year-old woman who presented with a pelvic cystic teratoma found to contain a well-differentiated malignant carcinoid at the time of surgical excision.

\section{Case report}

The patient is a 68 year-old female who presented with increasing abdominal girth, vague lower abdominal discomfort, and an $8 \mathrm{lb}$ weight gain over the past 12 months in the absence of changes in appetite or bowel habits. She was nulliparous, denied any vaginal bleeding after menopause, and reported a hysterectomy in the past. A $20 \mathrm{~cm}$ pelvic mass, consistent with a teratoma/dermoid cyst, was detected by CT scan. On physical exam, the lesion was protuberant and firm. Pre-operative colonoscopy was unsuccessful because of displacement of the sigmoid colon by extrinsic compression of the mass. CEA and CA-125 were within normal laboratory ranges $(3.3 \mathrm{ng} / \mathrm{mL}$ and $18.1 \mathrm{U} / \mathrm{mL}$, respectively). CA $19-9$, at 
98.8U/mL, was markedly elevated. The patient was informed of the findings and opted for non-operative management.

Follow-up CT imaging (Figures 1-2) 7 months after the initial scan demonstrated a complex cystic mass containing solid, fatty, and calcified components, occupying most of the pelvis and mid-abdomen. It remained unchanged since the previous imaging study. The patient agreed to undergo excision of the tumor. Macroscopic exam revealed a $15 \mathrm{~cm} \times 15 \mathrm{~cm}$ $\times 10 \mathrm{~cm}$ pink-tan cystic mass with a mesothelial lining. Upon pathological examination internal lining was red to dark brown and finely granular. It contained yellow cheesy material and dark brown fluid, with tufts of hair and a hard bony structure. Further pathologic analysis of the mass reported that immunohistochemical stains performed showed that the tumor cells were strongly and diffusely positive for synaptophysin, confirming the concomitant diagnosis of a neuroendocrine tumor. Histopathologically the mass was described as a well-differentiated, malignant carcinoid arising within a mature cystic teratoma. The patient had an unremarkable post-operative course and is doing well at follow up 3 months after operation. No post-operative chemotherapy was indicated. Immediate follow-up includes a repeat CT scan and colonoscopy in 3 months. Prognosis is excellent.

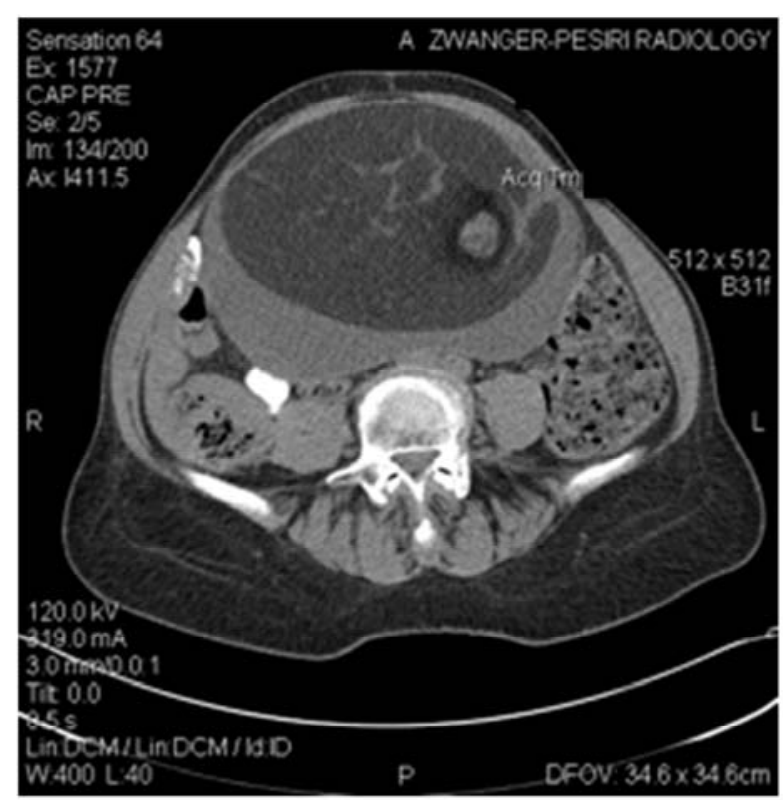

Figure 1. Abdominal CT scan demonstrating a large cystic mass with a small, central solid focus.

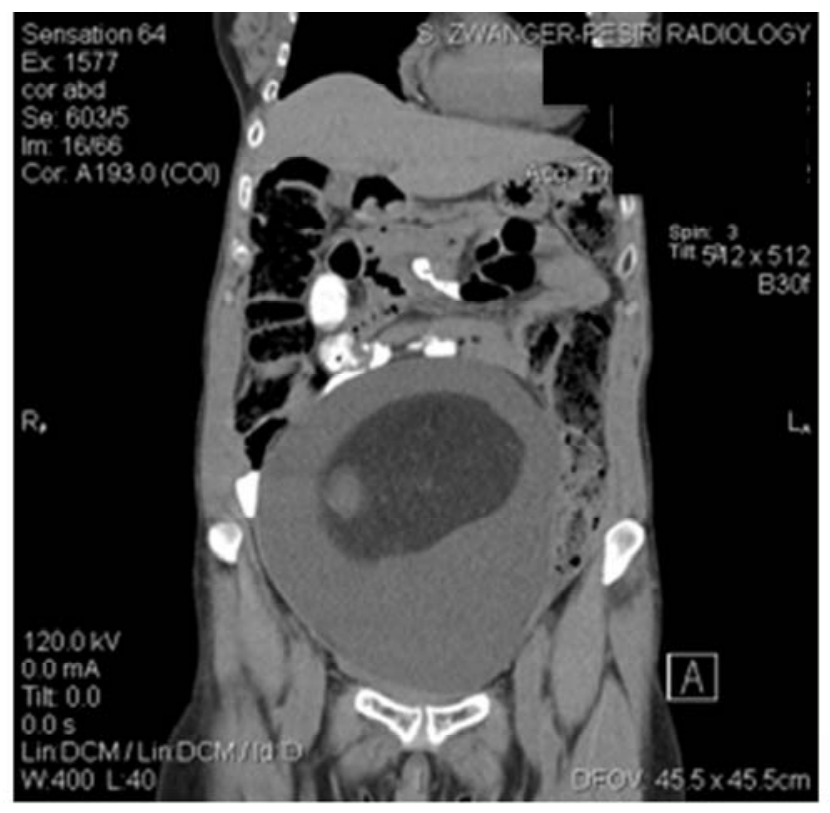

Figure 2. Coronal CT scan view of the mass

\section{Discussion}

Dermoid cysts, or mature cystic teratomas, contain cellular elements derived from all three germ cell layers and are lined with squamous epithelium containing skin appendages. Dermoid cysts are usually easy to identify during surgery by the presence of sebaceous fluid content and/or tufts of hair ${ }^{[2]}$. They are most frequently found in the sacrococcygeal region, ovaries, and testes. Occasionally, they also occur in extragonadal midline structures such as the anterior mediastinum, retroperitoneum, and pineal gland ${ }^{[3]}$.

Dermoid cysts present in all age groups, but are most common in the third and fourth decades of life. Malignant transformation may be observed in 1\%-2\% of cases. Squamous cell carcinoma accounts for $70 \%$ - $88 \%$ of such malignant cases, followed by adenocarcinoma ${ }^{[4]}$. 
Carcinoids are rare neuroendocrine tumors that arise from enterochromaffin cells and comprise $0.5 \%$ of all malignancies. They arise in regions of the body with high concentration of neuroendocrine cells, such as the gastrointestinal tract (68\%) and bronchopulmonary system (25\%). Approximately $10 \%$ of carcinoids secrete bioactive mediators, leading to carcinoid

syndrome ${ }^{[5,6]}$. The standard of treatment for carcinoid tumors includes debulking or complete surgical excision as early as possible given their potential for metastases ${ }^{[7]}$.

\section{Conclusion}

We present a very rare case of a malignant neuroendocrine tumor within a dermoid cyst that was successfully resected.

\section{Conflict of interest}

The authors declare that there is no conflict of interest statement.

\section{References}

[1] Pitt SC, Chen H. Chapter 19. Carcinoid Tumors. In: Morita SY, Dackiw AP, Zeiger MA, eds. McGraw-Hill Manual: Endocrine Surgery. New York: McGraw-Hill; http://www.accesssurgery.com/content.aspx?aID=6163770.

[2] Lin P, Falcone T, Tulandi T. Excision of ovarian dermoid cyst by laparoscopy and by laparotomy. Am J Obstet Gynecol. Sep 1995;173(3 Pt 1):769-71. http://dx.doi.org/10.1016/0002-9378(95)90338-0

[3] Gatcombe HG, Assikis V, Kooby D, Johnstone PA. Primary retroperitoneal teratomas: A review of the literature. J Surg Oncol. May 1 2004;86(2):107-13. PMid:15112254 http://dx.doi.org/10.1002/jso.20043

[4] Chiang AJ, La V, Peng J, Yu KJ, Teng NN. Squamous cell carcinoma arising from mature cystic teratoma of the ovary. Int J Gynecol Cancer. Apr 2011;21(3):466-74. PMid:21430455 http://dx.doi.org/10.1097/IGC.0b013e31820d3e5b

[5] Modlin IM, Lye KD, Kidd M. A 5-decade analysis of 13,715 carcinoid tumors. Cancer. Feb 15 2003;97(4):934-59. PMid:12569593 http://dx.doi.org/10.1002/cncr.11105

[6] Modlin IM, Lye KD, Kidd M. Carcinoid tumors of the stomach. Surg Oncol. Aug 2003;12(2):153-72. http://dx.doi.org/10.1016/S0960-7404(03)00034-3

[7] Maroun J, Kocha W, Kvols L, et al. Guidelines for the diagnosis and management of carcinoid tumors. Part 1: The gastrointestinal tract. A statement from a Canadian National Carcinoid Expert Group. Curr Oncol. Apr 2006;13(2):67-76. PMid:17576444 